\title{
Aspergilose pulmonar invasiva em receptor de transplante renal - relato de caso e revisão da literatura
}

\section{Invasive pulmonary aspergilosis in renal transplant recipient - case report and literature review}

Graziela Bastos Ribas de Aguiar ${ }^{1}$. Claudia Maria Costa de Oliveira ${ }^{2}$. Evelyne Santana Girão ${ }^{3}$. Sônia Leite Silva ${ }^{4}$. Paula Frassineti Castelo Branco Camurça Fernandes ${ }^{5}$.

1 Médica residente do Programa de Clínica Médica, Hospital Universitário Walter Cantídio (HUWC), Fortaleza, Ceará, Brasil. 2 Doutora em Ciências da Saúde, Médica Nefrologista e coordenadora do Transplante Renal, Hospital Universitário Walter Cantídio (HUWC), Universidade Federal do Ceará (UFC). Professora e coordenadora do mestrado Ensino em Saúde, Centro Universitário Christus (UniChristus), Fortaleza, Ceará, Brasil. 3 Mestre em Doenças Infecciosas e Parasitárias, Médica Infectologista no Hospital Universitário Walter Cantídio (HUWC), Universidade Federal do Ceará (UFC), Fortaleza, Ceará, Brasil. 4 Doutora em Farmacologia, Médica Nefrologista, Unidade de Transplante Renal, Hospital Universitário Walter Cantídio (HUWC), Universidade Federal do Ceará (UFC), Professora titular na Universidade de Fortaleza, Fortaleza, Ceará, Brasil. 5 Doutora em Medicina Interna e Terapêutica, Médica Nefrologista, Unidade de Transplante Renal, e Chefe do Serviço do Sistema Urinário, Hospital Universitário Walter Cantídio (HUWC), Universidade Federal do Ceará (UFC), Fortaleza, Ceará, Brasil.

\section{RESUMO}

Os autores relatam o caso de um receptor de transplante renal com aspergilose pulmonar invasiva no primeiro mês de transplante, que evoluiu para o óbito a despeito da terapia. Uma revisão da literatura foi realizada para descrever os principais aspectos dessa enfermidade e compará-los com as manifestações clínicas e laboratoriais do paciente em questão. O conhecimento sobre esta complicação após transplante de rim ou de outros órgãos é importante pois, devido à significativa taxa de mortalidade, a rapidez do diagnóstico é um fator determinante na sobrevida do paciente.

Palavras-chave: Transplante. Aspergilose. Rim.

\section{ABSTRACT}

The authors report the case of a renal transplant recipient with invasive pulmonary aspergillosis in the first month of transplantation, who evolved to death despite therapy. A literature review was performed to describe the main aspects of this disease and to compare them with the clinical and laboratory manifestations of the patient in question. The knowledge about this complication after transplantation of the kidney or other organs is important because, due to the significant mortality rate, the speed of diagnosis is a determining factor in patient survival.

Keywords: Transplantation. Aspergillosis. Kidney.

Autor correspondente: Graziela Bastos Ribas de Aguiar, Rua José Vilar 2180, apartamento 1201, Dionísio Torres, Fortaleza, Ceará. CEP: $60125-001$. Telefone: +55 85 99626-5879. E-mail: grazielabra@hotmail.com

Conflito de interesses: Não há qualquer conflito de interesses por parte de qualquer um dos autores.

Recebido em: 07 Jan 2017; Revisado em: 01 Fev 2017; Aceito em: 02 Fev 2017. 


\section{INTRODUÇÃO}

Aspergilose pulmonar invasiva (AI) ocorre em até 15\% dos receptores de transplante de órgãos sólidos, manifestando-se em $0,7 \%$ a $4 \%$ dos transplantados renais. ${ }^{1}$ É uma complicação importante nos receptores de transplante em geral, pois a taxa de mortalidade é de aproximadamente $22 \%{ }^{1}$

O principal determinante no aparecimento da doença é a intensidade da imunossupressão utilizada, independente do órgão transplantado. ${ }^{1} \mathrm{Na}$ prática, observa-se um atraso substancial no diagnóstico, o que pode comprometer o sucesso da terapia.

Os autores relatam um caso de $\mathrm{AI}$ em um paciente no primeiro mês de transplante renal (TxR) que, após 2 meses de doença, evoluiu para o óbito.

\section{RELATO DO CASO}

J.A.A., masculino, 42 anos, iniciou tratamento dialítico em julho de 1997, devido à glomerulonefrite membranoproliferativa, e foi transplantado com rim de doador falecido em março de 2016. Tinha antecedentes de hipertensão arterial sistêmica e anticorpos antifosfolípideo e anticoagulante lúpico positivos, porém, sem eventos trombóticos prévios. O índice de massa corporal (IMC) era de $18,75 \mathrm{~kg} / \mathrm{m}^{2}$. Painel reativo a linfócitos classe I de $80 \%$ e classe II de $47 \%$, com 3 mismatches HLA com o doador. Doador falecido, 33 anos, feminino, causa mortis encefalopatia hipóxica por parada cardiorrespiratória, creatinina terminal de $0,6 \mathrm{mg} / \mathrm{dl}$.

A terapia de indução da imunossupressão foi realizada com timoglobulina, e a manutenção, com tacrolimus, micofenolato sódico e prednisona. O tempo de isquemia fria foi de $25 \mathrm{~h} 14 \mathrm{~min}$, e evoluiu com função retardada do enxerto, sem outras complicações. Foi de alta hospitalar no $16^{\circ}$ dia de pós-operatório (PO), com creatinina de $2,5 \mathrm{mg} / \mathrm{dL}$ e em uso da medicação imunossupressora e profilática padrão, além de varfarina sódica.

Quatro dias após a alta $\left(20^{\circ} \mathrm{PO}\right)$, foi reinternado com quadro de dor em fossa ilíaca esquerda (ipsilateral ao enxerto), leucocitose (18.320 leucócitos/ $\mathrm{mm}^{3}$, com 16.854 neutrófilos/ $\mathrm{mm}^{3}$ ), creatinina $2,1 \mathrm{mg} / \mathrm{dL}$ e urocultura contaminada. O ultrassom com Doppler do enxerto renal mostrou sinais de leve enfermidade parenquimatosa, estudo dopplerfluxométrico normal, coleção heterogênea adjacente e antero-lateral ao enxerto. Foi tratado com piperacilina-tazobactam por 14 dias, recebendo alta no $37^{\circ} \mathrm{PO}$. Logo após a alta, passou a apresentar tosse seca, sendo reinternado 7 dias após o início dos sintomas $\left(44^{\circ} \mathrm{PO}\right)$. A radiografia de tórax mostrou opacidades bilaterais de padrão alveolar, marcadamente em terços médios, com volumes pulmonares preservados (Figura 1). Foi iniciado piperacilina-tazobactam e prova terapêutica para tuberculose pulmonar com rifampicina/isoniazida/pirazinamida/etambutol (RIPE), sendo o RIPE retirado após 2 resultados negativos no escarro pelo genexpert. As hemoculturas foram negativas.

No $14^{\circ}$ dia do inicio do quadro $\left(51^{\circ} \mathrm{PO}\right)$, apresentou piora clínica com dispneia e escarro hemoptoico, sendo iniciado meropenem, complexo lipídico de anfotericina B e suspenso o anticoagulante. A broncoscopia realizada no $19^{\circ}$ dia da doença $\left(56^{\circ} \mathrm{PO}\right)$ evidenciou discreto processo inflamatório bilateral difuso. O estudo do lavado brônquico mostrou 2.474 células, 597 hemácias, 1\% linfócitos, 3\% monócitos, 96\% neutrófilos; pesquisa de BAAR negativa; pesquisa de fungos com presença de hifas hialinas septadas; cultura para germes piogênicos negativa e cultura para fungos com isolamento de Aspergillus sp.

Figura 1. Raio-x de tórax da internação: opacidades bilaterais de padrão alveolar, marcadamente em terços médios, com volumes pulmonares preservados.

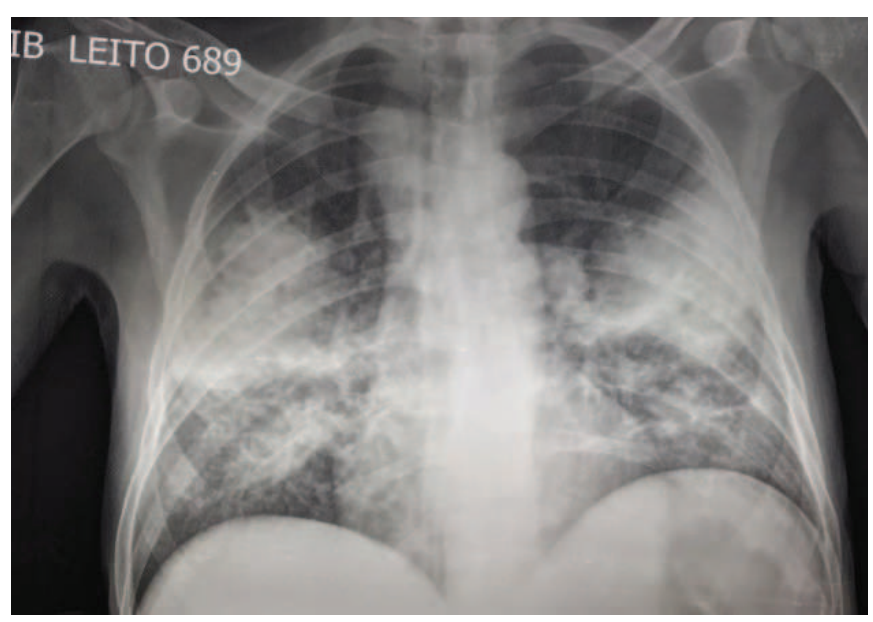

Outros exames realizados foram: ultrassom abdominal com hepatoesplenomegalia homogênea e padrão dopplerfluxométrico da veia porta habitual; ferritina acima de $10.000 \mathrm{ng} / \mathrm{mL}$ e índice de saturação de transferrina de $70 \%$; a pesquisa de mutação do gene de hemocromatose sugeriu hemossiderose por suplementação de ferro na diálise (C282Y: homozigoto normal e H63D: heterozigoto); reação em cadeia da polimerase para citomegalovírus não reagente; aspartato aminotransferase $240 \mathrm{UI} / \mathrm{L}$; alanina aminotransferase 191 $\mathrm{UI} / \mathrm{L}$; gama glutamil transferase $350 \mathrm{UI} / \mathrm{L}$; fosfatase alcalina $1013 \mathrm{U} / \mathrm{L}$; desidrogenase lática $428 \mathrm{U} / \mathrm{L}$; albumina 2,5 g/dL.

No $30^{\circ}$ dia do início da doença ( $\left.67^{\circ} \mathrm{PO}\right)$, a anfoterocina $\mathrm{B}$ foi substituída por voriconazol intravenoso, que foi suspenso 5 dias depois por piora da função renal (creatinina aumentou de $0,9 \mathrm{mg} / \mathrm{dL}$ para $1,3 \mathrm{mg} / \mathrm{dL}$, com clearance de creatinina $<50 \mathrm{~mL} / \mathrm{min} / 1,73 \mathrm{~m}^{2}$ ). Foi reiniciado o complexo lipídico de anfotericina B associado ao voriconazol por sonda nasoenteral, já que a via oral de administração não está comumente associada à lesão renal.

O paciente foi admitido na terapia intensiva (UTI) no $36^{\circ}$ dia da doença, devido à piora da dispneia e dos escarros hemoptoicos. A tomografia computadorizada de alta resolução (TCAR) de tórax sem contraste neste dia mostrou pulmões de volumes reduzidos, consolidações extensas contendo escavações situadas em segmentos posteriores em ambos os lobos superiores, segmento lateral do lobo médio e segmento apical de lobo inferior direito, demonstrando halo hipoatenuante. 
Demais segmentos pulmonares de densidade parenquimatosa heterogênea caracterizada por espessamento septal fino e regular, além de esparsas bandas parenquimatosas; derrame pleural de pequeno volume, múltiplos linfonodos hilares e brônquio-pulmonares bilaterais, e mediastino apresentando adenomegalias calcificadas em cadeias subcarinal e paratraqueal direita (Figuras 2 e 3).

Figura 2. Tomografia computadorizada de tórax: consolidações extensas contendo escavações bilaterais.

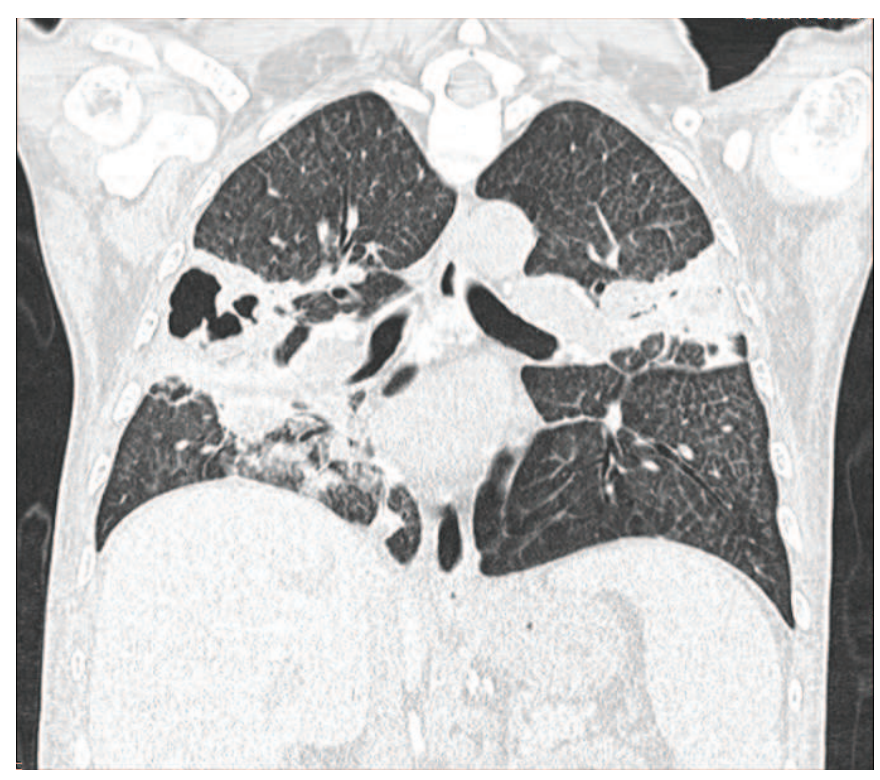

Figura 3. Tomografia computadorizada de tórax: consolidações extensas contendo escavações bilaterais.

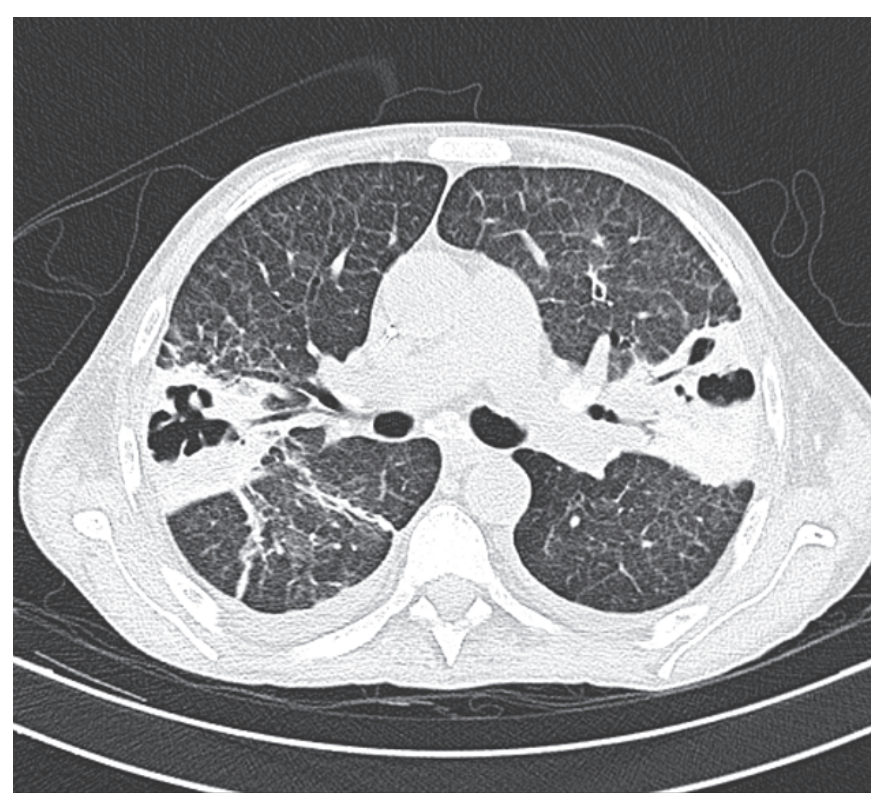

No $43^{\circ}$ dia da doença o paciente apresentou insuficiência respiratória, sendo realizada a intubação orotraqueal. Não foi indicada a retirada cirúrgica dos aspergilomas, devido à grande extensão do acometimento pulmonar. Na UTI foi tratado com polimixina $\mathrm{B}$, linezolida, tigeciclina e vancomicina, além de drogas vasoativas. Após persistente piora clínica/laboratorial, paciente foi a óbito no $52^{\circ}$ dia do início da doença $\left(89^{\circ} \mathrm{PO}\right)$ por choque séptico.

\section{DISCUSSÃO}

Apesar da baixa incidência de AI pós-transplante renal, que ocorre em 0,7 a $4 \%$ dos casos, ${ }^{1}$ comparada à AI pós-transplante de outros órgãos sólidos [fígado: 1 a 9,2\%, ${ }^{2}$ pulmão: 4 a 23,3\% ${ }^{3}$ e coração: 1 a $14 \%{ }^{4}$ ], a doença contribui significativamente na morbimortalidade desse grupo, uma vez que a mortalidade encontra-se em torno de $70 \%$.

O principal determinante do aparecimento da doença, independente do órgão transplantado, é a intensidade da imunossupressão utilizada. Entretanto, os fatores de risco diferem de acordo com o órgão transplantado. No TxR, uso de corticóide em doses altas e por tempo prolongado, falência do enxerto que requer hemodiálise e terapia imunossupressora potente são os principais fatores de risco. ${ }^{1}$

A doença pode ser assintomática nas fases iniciais, evoluindo com tosse, hemoptise, dor torácica e dispneia. Destes sintomas, nosso paciente apenas não referiu dor torácica. Um estudo retrospectivo europeu realizado entre 2000 e 2013, envolvendo 112 transplantados renais com AI diagnosticada ou provável, demonstrou que os sintomas iniciais mais comuns são tosse, febre e expectoração (observados em 75,5\%, 63,1\% e 57,3\% dos casos, respectivamente). Dispneia ocorreu em 22,5\% dos casos, e hemoptise, em 5,4\%. ${ }^{5}$ Um substancial atraso no diagnóstico dificulta o tratamento bem-sucedido, devendo haver um bom índice de suspeição e investigação diagnóstica adequada.

A cultura do aspirado traqueal (AT) tem baixa sensibilidade, e o fungo pode ser detectado somente em estágios tardios da doença. Por outro lado, uma cultura positiva no AT nem sempre indica uma doença invasiva. No lavado brônquico do referido paciente, o Aspergillus sp. foi rapidamente isolado.

$\mathrm{Na}$ ausência de cultura, a detecção de galactomanana, um polissacarídeo da parede do Aspergillus spp., pode ser um marcador diagnóstico de AI. ${ }^{6}$ A antigenemia seriada com galactomanana, além de facilitar o diagnóstico precoce, pode ajudar na avaliação da resposta terapêutica. Outro marcador potencial é o $\beta$-D-glucana, cuja presença significa infecção fúngica invasiva, porém o teste não é específico. ${ }^{6}$

A TCAR mostra, geralmente, nódulos envoltos por halo em vidro fosco ("sinal do halo"), ou áreas de consolidação segmentares (algumas vezes em forma de cunha) com base voltada para a superfície pleural, associadas ou não a áreas de atenuação em vidro fosco. Estes achados correspondem a infartos hemorrágicos. ${ }^{7}$

No diagnóstico diferencial da aspergilose pulmonar invasiva devem ser incluídas doenças infecciosas causadas por Zigomicetos, Fusarium spp., Scedosporium spp., Pseudomonas aeruginosa e Norcadia spp., ${ }^{6}$ além de tuberculose e outras infecções bacterianas, como foi aventado neste caso. 
Devido à rapidez da progressão da doença, recomenda-se o tratamento precoce nos casos suspeitos, enquanto a avaliação diagnóstica é conduzida. ${ }^{1}$ Um ensaio clínico controlado randomizado mostrou que o voriconazol, quando comparado à anfotericina B, apresenta melhor resposta terapêutica, melhor sobrevida e maior segurança. Ele é o tratamento de primeira escolha, sendo a formulação intravenosa recomendada para pacientes graves. ${ }^{6}$

No presente caso, a anfotericina B foi iniciada empiricamente e, após a confirmação diagnóstica e ausência de melhora clínica e radiológica, ela foi substituída pelo voriconazol intravenoso, este foi suspenso após 5 dias por piora da função renal (creatinina aumentou de $0,9 \mathrm{mg} / \mathrm{dL}$ para 1,3 $\mathrm{mg} / \mathrm{dL}$ ), já que o voriconazol endovenoso deve ser evitado em pacientes com clearance de creatinina abaixo de $50 \mathrm{~mL} /$ $\mathrm{min} / 1,73 \mathrm{~m}^{2} .{ }^{8}$ A nefrotoxicidade do voriconazol intravenoso deve-se ao veículo sulfobutileter-beta-ciclodextrina, que é um agente solubilizante excretado por via renal e está

\section{REFERÊNCIAS}

1. Singh NM, Husain S. Aspergillosis in solid organ transplantation. Am J Transplant. 2013;13(6):228-41.

2. Morgan J, Wannemuehler KA, Marr KA, Hadley S, Kontoyiannis $\mathrm{DP}$, Walsh TJ, et al. Incidence of invasive aspergillosis following hematopoietic stem cell and solid organ transplantation: interim results of a prospective multicenter surveillance program. Med Mycol. 2005;43(Suppl 1):S49-S58.

3. Husain S, Paterson DL, Studer S, Pilewski J, Crespo M, Zaldonis $\mathrm{D}$, et al. Voriconazole prophylaxis in lung transplant recipients. Am J Transplant. 2006;6(12): 3008-16.

4. Munoz P, Singh N, Bouza E. Treatment of solid organ transplant patients with invasive fungal infections: should a combination of antifungal drugs be used? Curr Opin Infect Dis. 2006;19(4):365-70.

5. López-Medrano F, Fernández-Ruiz M, Silva JT, Carver PL, van Delden C, Merino E, et al. Clinical presentation and determinants of mortality of invasive pulmonary aspergillosis in kidney transplant recipients: a multinational cohort study. Am J Transplant. 2016;16(11):3220-34.

6. Sales MP. Curso de atualização - micoses. Capítulo 5 - Aspergilose: do diagnóstico ao tratamento. J Bras Pneumol. 2009;35(12):1238-44. associado à nefrotoxicidade em ratos, causando vacuolização dos túbulos renais. ${ }^{9,10}$

A combinação terapêutica geralmente não é recomendada como primeira escolha, mas pode ser utilizada em casos de intolerância ou refratariedade. ${ }^{6}$ A duração do tratamento é normalmente de 6 a 12 semanas, porém, pacientes imunossuprimidos devem manter o medicamento até que ocorra melhora da imunossupressão e reabsorção das lesões. ${ }^{6}$

As taxas de mortalidade variam de 60 a $90 \%$ e são dependentes das condições clínicas subjacentes do paciente. ${ }^{11} \mathrm{O}$ paciente descrito, além da imunossupressão medicamentosa, também apresentava desnutrição e hemossiderose, o que provavelmente contribuiu para o desfecho desfavorável.

Concluindo, paciente após um mês de TxR apresentou AI, evoluindo para o óbito 52 dias após o início da doença, a despeito do tratamento antifúngico.

7. Leão RC, Marchiori E, Rodrigues R, Souza AS Jr, Gasparetto EL, Escuissato DL. Tomografia computadorizada na avaliação da aspergilose pulmonar angioinvasiva em pacientes com leucemia aguda. Radiol Brasil. 2006;39(5):327-31.

8. VFEND: voriconazole. Highlights of prescribing information [Internet]. New York: Roering; 2015 [acesso em: 2016 dez 23]. Disponível em: http://labeling.pfizer.com/ShowLabeling. aspx?id $=618$

9. FDA Antiviral Drugs Advisory Committee. Briefing document for voriconazole (oral and intravenous formulations) [Internet]. New York: Pfizer; 2001 [acesso em: 2016 nov 23]. Disponível em: http:// www.fda.gov/ohrms/dockets/ac/01/briefing/3792b2_01_pfizer.pdf

10. Luke DR, Tomaszewski K, Damle B, Schlamm HT. Review of the basic and clinical pharmacology of sulfobutylether-beta-cyclodextrin (SBECD). J Pharm Sci. 2010;99(8):3291-301.

11. Patterson TF, Kirkpatrick WR, White M, Hiemenz JW, Wingard JR, Dupont B, et al. Invasive aspergillosis. Disease spectrum, treatment practices, and outcomes. I3 Aspergillus Study Group. Medicine (Baltimore) 2000;79(4):250-60.

\section{Como citar:}

Aguiar GB, Oliveira CM, Girão ES, Silva SL, Fernandes PF. Aspergilose pulmonar invasiva em receptor de transplante renal - relato de caso e revisão da literatura. Rev Med UFC. 2017 set-dez;57(3):62-65. 